\title{
Meclizine Hydrochloride
}

National Cancer Institute

\section{Source}

National Cancer Institute. Meclizine Hydrochloride. NCI Thesaurus. Code C29245.

The hydrochloride salt form of meclizine, a synthetic piperazine with anti-emetic, sedative and histamine $\mathrm{H} 1$ antagonistic properties. Meclizine hydrochloride blocks the $\mathrm{H} 1$ histamine receptor and prevents the symptoms that are caused by histamine activity on capillaries, bronchial and gastrointestinal smooth muscles, including vasodilation, increased capillary permeability, bronchoconstriction, and spasmodic contraction of gastrointestinal smooth muscles. Meclizine hydrochloride may exert its antiemetic effects by its anticholinergic actions or due to a direct effect on the medullary chemoreceptive trigger zone. 